\title{
There is no role for focal therapy in prostate cancer
}

\author{
Peter Black, MD, FRCSC
}

T he increasing interest in focal therapy for prostate cancer derives from the paucity of prospective randomized studies to guide treatment for this disease, and the concern that the current therapies incur excessive patient morbidity. Radical prostatectomy, external beam radiotherapy and brachytherapy are the established standard treatments for locally confined prostate cancer. However, owing to a lack of data, we struggle with individual patients to decide which modality is best, and in many cases we do not even know if we are enhancing survival over observation alone. The Scandinavian Prostate Cancer Group demonstrated a modest improvement of survival in a cohort of nonscreened men who underwent radical prostatectomy compared with those who underwent no primary therapy. ${ }^{1}$ With the advent of prostate-specific antigen (PSA) screening, however, we are detecting an increasing number of indolent cancers ${ }^{2}$ and it is not certain whether the same survival advantage would be found in a screened population. Furthermore, with overdetection has come overtreatment, and overtreatment in turn gives rise to numerous associated adverse effects and potential impairment of quality of life. ${ }^{3}$

Focal therapy has arisen in this context as a treatment that can ablate prostate cancer with minimal collateral damage, thereby side-stepping some of the treatment dilemma. Focal therapy involves subtotal ablation of the prostate with one of several energy sources, including cryotherapy, high intensity focused ultrasound and photodynamic therapy. Targeting the tumour or one specific region of the prostate is done with the expectation of avoiding the adverse effects of total-gland therapy, especially incontinence and impotence. ${ }^{4}$

There is, however, little evidence to support the application of focal therapy. First, its efficacy remains unproven, and, second, it has yet to be demonstrated that it will reduce side effects of treatment. Furthermore, while we await clinical trials to answer these fundamental questions, there are significant conceptual difficulties with focal therapy.

The principal conceptual shortcoming of focal therapy is the fact that prostate cancer is often multifocal. Only about $20 \%$ of tumours are unilateral and unifocal..$^{5-7}$ There are 2 ways around this issue of multifocality. Either one is able to identify each focus and treat each appropriately (or limit focal therapy to unifocal prostate cancer), or one assumes that not each focus requires treatment. This latter argument is made frequently based on the idea that the largest tumour (the index lesion) is driving the potential progression of the disease, and the secondary lesions are indolent. ${ }^{5}$ Yet we know that prostate cancer, like most cancers, is a heterogeneous disease, and we do not know in all cases that these satellite lesions do not harbour a biologically significant focus of disease. ${ }^{8}$ This is currently a leap of faith, particularly since we are unable to monitor the growth of secondary lesions because of our inability to adequately image the prostate.

The inability to image foci of prostate cancer is the second principal conceptual difficulty with focal therapy. Improvements continue to be made especially in magnetic resonance imaging (MRI) of the prostate, but we are still far from being able to accurately identify every index lesion of prostate cancer on MRI, let alone secondary sites of disease. ${ }^{9}$ The alternative strategy is to map the cancer by systematic biopsy, but this too has unproven reliability. ${ }^{10-12}$ Furthermore, saturation biopsies are expensive and they are not without complications. ${ }^{13,14}$ There are many anecdotal stories of subsequent difficulties with the posterior dissection and nervesparing at the time of radical prostatectomy.

A third shortcoming is the need to define outcome variables. These therapies are ablative, so that a threshold PSA appears most appropriate (e.g., PSA > $0.5 \mu \mathrm{g} / \mathrm{L}$ ), but dynamic definitions as used for radiotherapy have also been proposed. ${ }^{15,16}$ This will need to be addressed with top priority if focal therapy is to be studied in a systematic fashion.

Conceptually, we should really be comparing focal therapy to active surveillance, since both are targeted at the same population of low-risk patients. Active surveillance

The purpose of the Point / Counterpoint section is to encourage vigorous and informed discussion on controversial issues in urology through the presentation of diverse opinions. We aim for a dispassionate discussion of controversies, recognizing that strong passions may exist in support of some positions. 
itself is an unproven management strategy for prostate cancer, although it is currently being assessed in 2 prospective randomized trials, including the Surveillance Therapy Against Radical Treatment (START) Trial and the Prostate Cancer Intervention Versus Observation Trial (PIVOT), in addition to the Canary registry trial. We need to overcome the tendency for automatic treatment of every prostate cancer that is diagnosed - overdetection does not have to lead to overtreatment. ${ }^{3}$ The principal obstacle to active surveillance is our limited ability to predict which cancers can be safely observed without subsequent disease progression our concern for undertreatment. At the same time, it is difficult for both the treating physician and the patient to accept that a cancer has been diagnosed but is not being treated. If we were able to remove the uncertainty of active surveillance by being able to define risk better and detect progression reliably, then the interest in focal therapy would likely dwindle.

The experience with active surveillance should be instructive for focal therapy. A recent series from Memorial SloanKettering Cancer Center, for example, found a high rate of higher risk disease in patients who fulfilled criteria for active surveillance but underwent radical prostatectomy. ${ }^{17}$ The investigators identified pT3 cancer in $11 \%$ and Gleason pattern 4 in $49 \%$ of patients. Five of 8 patients with no cancer shown on second biopsies went on to have Gleason pattern 4 cancer on radical prostatectomy. These findings reinforce that we are poor at assessing risk, which is the foundation of focal therapy.

The International Task Force on Prostate Cancer and the Focal Lesion Paradigm has been established and has published a position statement. ${ }^{4}$ This group refers to focal therapy as "attractive from a conceptual perspective" and suggests that "cases ... should be collected prospectively in a database for future analysis." They readily acknowledge that criteria for patient selection have yet to be determined and summarize that "this procedure may fill a void in the therapeutic options available to men who are potential candidates for active surveillance who prefer therapy." Is it reasonable to submit patients to an unproven therapy with poorly defined adverse effects just for the sake of "doing something"? Also, since focal therapy is currently aimed at lesions that we believe may not actually require therapy, it is going to be difficult to show the superiority of any treatment in this population.

There is currently no role for focal therapy in the management of localized prostate cancer. Our efforts should focus on improving methods of screening, diagnosis and risk stratification to allow optimal identification of patients who are suitable for active surveillance, and those with more significant disease should go on to radical prostatectomy or radiotherapy — the established standard therapies.

Assistant Professor, Department of Urologic Sciences, University of British Columbia, Vancouver, BC

This article has been peer reviewed.

Competing interests: None declared.

\section{References}

1. Bill-Axelson A, Holmberg L, Filen F, et al. Radical prostatectomy versus watchful waiting in localized prostate cancer: the Scandinavian prostate cancer group-4 randomized trial. J Natl Cancer Inst 2008; 100:1144-54.

2. Schroder FH. Screening for prostate cancer (PC)-an update on recent findings of the European Randomized Study of Screening for Prostate Cancer (ERSPC). Urol Oncol 2008;26:533-41.

3. Miller $D C$, Gruber SB, Hollenbeck BK, et al. Incidence of initial local therapy among men with lower-risk prostate cancer in the United States. J Natl Cancer Inst 2006;98:1134-41.

4. Eggener SE, Scardino PT, Carroll PR, et al. Focal therapy for localized prostate cancer: a critical appraisal of rationale and modalities. J Urol 2007;178:2260-7.

5. Wise AM, Stamey TA, McNeal JE, et al. Morphologic and clinical significance of multifocal prostate cancers in radical prostatectomy specimens. Urology 2002;60:264-9.

6. Cheng L, Jones TD, Pan $C X$, et al. Anatomic distribution and pathologic characterization of small-volume prostate cancer $(<0.5 \mathrm{~mL})$ in whole-mount prostatectomy specimens. Mod Pathol 2005; 18:1022-6.

7. Mouraviev V, Mayes JM, Sun L, et al. Prostate cancer laterality as a rationale of focal ablative therapy for the treatment of clinically localized prostate cancer. Cancer 2007;110:906-10.

8. Gburek BM, Kollmorgen TA, Qian J, et al. Chromosomal anomalies in stage DI prostate adenocarcinoma primary tumors and lymph node metastases detected by fluorescence in situ hybridization. J Urol 1997; 157:223-7.

9. Testa C, Schiavina R, Lodi R, et al. Prostate cancer: sextant localization with MR imaging, MR spectroscopy, and 11C-choline PET/CT. Radiology 2007;244:797-806.

10. Barzell WE, Melamed MR. Appropriate patient selection in the focal treatment of prostate cancer: the role of transperineal 3-dimensional pathologic mapping of the prostate - a 4-year experience. Urology 2007;70(Suppl):27-35.

11. Bott SR, Henderson A, Halls JE, et al. Extensive transperineal template biopsies of prostate: modified technique and results. Urology 2006;68:1037-41.

12. Pinkstaff DM, Igel TC, Petrou SP, et al. Systematic transperineal ultrasound-guided template biopsy of the prostate: three-year experience. Urology 2005;65:735-9.

13. Akbal C, Turker P, Tavukcu HH, et al. Erectile function in prostate cancer-free patients who underwent prostate saturation biopsy. Eur Urol 2008;53:540-4.

14. Simon J, Kuefer R, Bartsch G Jr, et al. Intensifying the saturation biopsy technique for detecting prostate cancer after previous negative biopsies: a step in the wrong direction. BJU Int 2008; 102:459-62.

15. Poissonnier L, Chapelon JY, Rouviere 0 , et al. Control of prostate cancer by transrectal HIFU in 227 patients. Eur Urol 2007;51:381-7.

16. Lee HM, Hong JH, Choi HY. High-intensity focused ultrasound therapy for clinically localized prostate cancer. Prostate Cancer Prostatic Dis 2006;9:439-43.

17. Berglund RK, Masterson TA, Vora KC, et al. Pathological upgrading and up staging with immediate repeat biopsy in patients eligible for active surveillance. J Urol 2008;180:1964-8.

Correspondence: Dr. Peter Black, Department of Urologic Sciences, University of British Columbia, 4480 Oak St., Vancouver BC V6H 3V4; fax 604 875-4637; pblack@interchange.ubc.ca 